\title{
www.czasopisma.pan.pl \\ Studies on the Gases Emission under High Temperature Condition from Moulding Sands Bonded by Modified Starch CMS-Na
}

\author{
K. Kaczmarska *, A. Bobrowski, S. Żymankowska-Kumon, B. Grabowska \\ AGH University of Science and Technology, Faculty of Foundry Engineering, \\ Reymonta 23, 30-059 Kraków, Poland \\ * Corresponding author. E-mail address: karolina.kaczmarska@agh.edu.pl
}

Received 30.06.2016; accepted in revised form 02.09.2016

\begin{abstract}
Emission of gases under high temperature after pouring molten metal into moulds, which contain the organic binder or other additives (solvents or curing agent), may be an important factor influencing both on the quality of the produced castings, and on the state of environment. Therefore, a comprehensive study of the emitted gases would allow to determine restrictions on the use of the moulding sands in foundry technologies, eg. the probability of occurrence of casting defects, and identify the gaseous pollutants emitted to the environment. The aim of the research presented in this paper was to determine the amount of gases that are released at high temperatures from moulding sands bonded by biopolymer binder and the quantitative assessment of the emitted pollutants with particular emphasis on chemical compounds: benzene, toluene, ethylbenzene and xylenes (BTEX). The water-soluble modified potato starch as a sodium carboxymethyl starch with low (CMS-NaL) or high (CMS-Naн) degree of substitution was a binder in the tested moulding sands. A tests of gases emission level were conducted per the procedure developed at the Faculty of Foundry Engineering (AGH University of Science and Technology) involving gas chromatography method (GC). The obtained results of the determination of amount of BTEX compounds generated during the decomposition process of starch binders showed lower emission of aromatic hydrocarbons in comparison with binder based on resin Kaltharz U404 with the acidic curing agent commonly used in the foundries.
\end{abstract}

Keywords: Innovative moulding materials, Sodium carboxymethyl starch, Gas emission, BTEX

\section{Introduction}

Studies on the application of starch and its modified form (derivatives) in various industries are conducted in many research facilities. In the foundry industry, the natural (in native form) starch is also used eg. as a binder or additive to moulding sands [1]. However, the modified starch is clearly preferable to applying in this role. Starch derivatives are more interesting materials because in contrast to native form they are soluble in cold water and form viscous stable solutions with good adhesiveness $[2,3]$.
Also on Faculty of Foundry Engineering (AGH University of Science and Technology) are conducted research on the assessment of the effectiveness of the application water-soluble derivatives of biopolymers, including starch, as the main component of binders in moulding sands and as a additives to the green sands [4-6]. The newly developed binder for moulding technologies are sodium carboxymethyl starches (CMS-Na) with varying degree of modification. Products are obtained in the reaction of carboxymethylation [6]. The essence of this modifications method is the introduction of a hydrophilic group in the glucopyranose ring by the etherification. This process is 
carried out in order to stabilize aqueous solutions of starch and reduce its tendency to retrogradation at low temperature [7]. Carboxymethylation reaction is conducted in two stages in accordance with the course of the etherification in Williamson reaction, and the characteristic feature of the etherified starch is a degree of substitution (DS), which is the average number of carboxymethyl groups $\left(-\mathrm{CH}_{2} \mathrm{COOH}\right)$ or sodium carboxymethyl groups $\left(-\mathrm{CH}_{2} \mathrm{COONa}\right)$ substituted in glucopyranose unit (the monomer of starch) [8]. Results of research on applications of sodium carboxymethyl starch in foundry demonstrated that with increasing degree of substitution of modified starch it is possible to increase the strength of moulds and obtaining the higher wear resistance $[3,6]$.

From the viewpoint of environmental protection, important advantage of binder CMS-Na is about $100 \%$ biodegradability in the presence of microorganisms, and the products of its biodegradation are not a threat to the environment [6]. Continuing environmental studies, the research aimed at qualitative and quantitative analysis of volatile products emitted in conditions of high temperature from moulding sand with binders CMS-Na with varying degrees of substitution were carried out.

\section{Materials}

\subsection{Binder}

As the binder in the moulding sands were used the two products obtained from native potato starch in etherification method [3]. Binders in the form of the sodium salt of carboxymethyl starch were applied in solid state (powder) and were introduced in a dry state to the mixer. The selected characteristic parameters of the binders are shown in Table 1.

Table 1.

The selected characteristic parameters of the binders

\begin{tabular}{lcc}
\hline Parameter & \multicolumn{2}{l}{ Binder } \\
\cline { 2 - 3 } & CMS-NaL & $\mathrm{CMS}-N a_{\mathrm{H}}$ \\
\hline $\begin{array}{l}\text { Degree of } \\
\text { substitution }\end{array}$ & 0.2 & 0.9 \\
\hline $\begin{array}{l}\text { Plastic viscosity 5\% } \\
\text { solution. Pa·s }\end{array}$ & 4.643 & 5.013 \\
\hline $\begin{array}{l}\text { Desizing time 5\% } \\
\text { solution }\end{array}$ & max. 120 & max. 60 \\
\hline pH 5\% solution & 11.4 & 9.6 \\
\hline $\begin{array}{l}\text { Origin of the } \\
\text { material }\end{array}$ & $\begin{array}{l}\text { Xenon, } \\
\text { Poland }\end{array}$ & $\begin{array}{c}\text { West Pomeranian University } \\
\text { of Technology Szczecin. } \\
\text { Poland }\end{array}$ \\
\hline
\end{tabular}

\subsection{Samples of moulding sands}

The BTEX emission measurements were performed on samples of moulding sands prepared from 100 parts by weight of silica grain sand (Sibelco Poland; main fraction: 0.20/0.16/0.32 $\mathrm{mm}$ ), 2.5 parts by weight of powdered starch binder and 5.0 parts by weigh of distilled water as a solvent. The dry ingredients were stirred in the laboratory roller mixer for 1 minute, then distilled water was added. The stirring of all ingredients together was continued for 3 minutes. Standard cylindric-shaped samples were prepared from moulding sand and they were cured immediately after formation by method using an electromagnetic field of the microwave power of $800 \mathrm{~W}$ and frequency of $2.45 \mathrm{GHz}$, time of curing was $240 \mathrm{~s}$ in microwave device INOTEC MD 10940; temperature within a sample was approx. $100{ }^{\circ} \mathrm{C}$. Cured samples were removed from the microwave device and cooled down in a desiccator.

\section{Methodology}

The quantitative and qualitative assessment of gases emission from the moulding sand was conducted according to the procedure developed at the Faculty of Foundry Engineering AGH [9]. Pouring temperature of cast iron was $1300^{\circ} \mathrm{C}$. During this process the volume of emitted gases was recorded. At the same time, thermal decomposition products of binder were adsorbed on activated carbon $[9,10]$. Then, in the standard course of the proceedings, adsorbed products were eluted to obtaining research material for the quantitative analysis of aromatic hydrocarbons. Analysis of the volatile products, with particular emphasis on the BTEX compounds was conducted by gas chromatography method with the use of the flame-ionising detector (GC-FID), equipped with the capillary chromatographic column RXI 5Sil-MS (Restek) of a length $30 \mathrm{~m}$ and internal diameter $0,25 \mathrm{~mm}$ [10].

\section{Results and discussion}

\subsection{The gases emission from moulding sands}

Figure 1 shows the results of emissivity of gases from moulding sands recorded after the pouring molten cast iron into the mould.

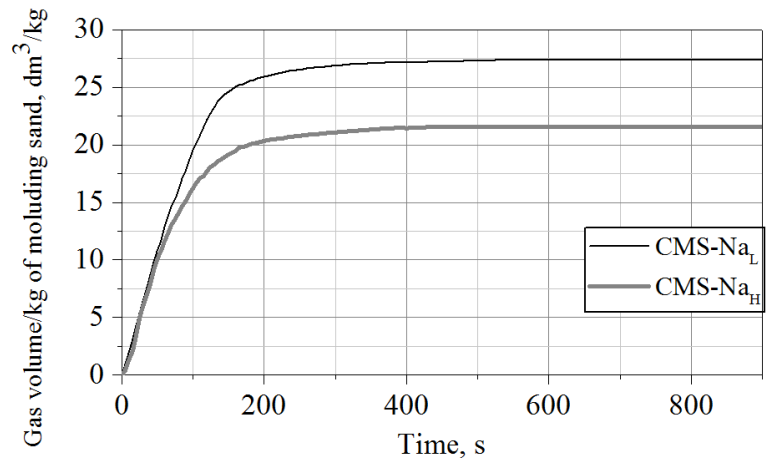

Fig. 1. Emissivity of gases in time from the tested moulding sands after pouring molten cast iron into the mould

Figure 2 shows a comparison between gas evolution rate from the both tested moulding sands with binders CMS-Na after pouring molten alloy into the cured moulds. 


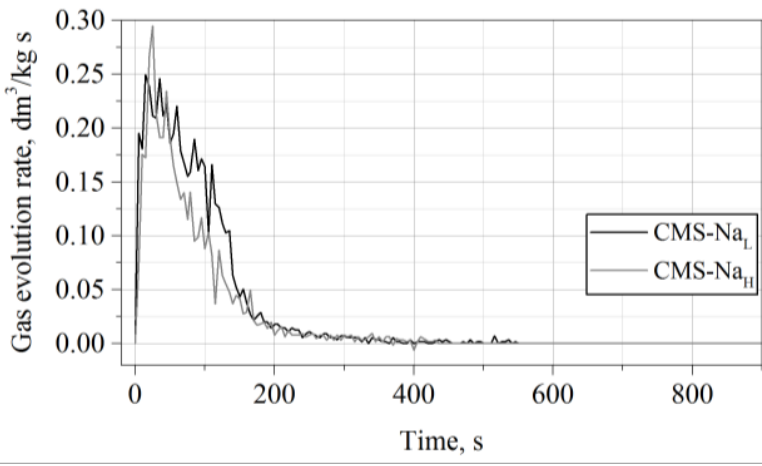

Fig. 2. Gas evolution rate from the tested moulding sands after pouring cast iron into the mould

Table 2 contains the essential parameters characterizing gas emission from the moulding sands with CMS-NaL and CMS-NaH.

In addition, for comparison, table 2 shows the results for moulding sand containing 1 parts by weight of resin Kaltharz $\mathrm{U} 404$ (furan resin with minimum $75 \%$ furfuryl alcohol $\mathrm{C}_{4} \mathrm{H}_{3} \mathrm{O}$ $\mathrm{CH}_{2}-\mathrm{OH}$ content; Hüttenes Albertus) and 0.5 parts by weight of curing agent (acid catalyst containing $65 \%$ p-Toluenesulfonic acid $\mathrm{CH}_{3} \mathrm{C}_{6} \mathrm{H}_{4} \mathrm{SO}_{3} \mathrm{H}$; Hüttenes Albertus) and 100 parts by weight of grain sand [11].

Table 2.

Results of gases emission from the moulding sands

\begin{tabular}{lccc}
\hline Gases emission & \multicolumn{3}{c}{ The type of binder in moulding sand } \\
\cline { 2 - 4 } & CMS-NaL & CMS-NaH & $\begin{array}{c}\text { Kaltharz } \\
\text { U404 }\end{array}$ \\
\hline $\begin{array}{l}\text { Gas volume } / \mathrm{kg} \text { moulding } \\
\text { sand, } \mathrm{dm}^{3} / \mathrm{kg}\end{array}$ & 27.4 & 21.5 & $33.0^{*}$ \\
\hline $\begin{array}{l}\text { Gas volume obtained from 1 g } \\
\text { of binder, } \mathrm{dm}^{3} / \mathrm{g} \text { binder }\end{array}$ & 1.12 & 0.86 & $2.23^{*}$ \\
\hline $\begin{array}{l}\text { Maximum } \mathrm{gas} \text { evolution rate } \\
(\mathrm{dV} / \mathrm{dt}), \mathrm{dm}^{3} / \mathrm{kg} \cdot \mathrm{s}\end{array}$ & 0.25 & 0.29 & $0.27^{*}$ \\
\hline
\end{tabular}

* resin cured by chemical agent [11]

Degradation of starch binders was the multi-stage process as evidenced by numerous peaks shown in Figure 2. The largest volume of the gas was generated from the both moulding sands with CMS-Na in the first $100 \mathrm{~s}$, when there could be effected evaporation of water (solvent or constitutional) and formation of the major gaseous products of thermal degradation of the starch binder. Presumably, the level of emission from these moulding sands could be due to intensive evaporation of residual water remaining in the moulding sand after the microwave curing process.

Analyzing the curves of the kinetics of gases emission from the moulding sands bonded by the CMS-Na with varying degrees of substitution was noted that moulding sand with CMS-NaL was characterised by higher gas emission - total generated gases were stabilized after $500 \mathrm{~s}$ at approx. $27.4 \mathrm{dm}^{3} / \mathrm{kg}$, while the moulding sand with the binder CMS-NaH after pouring the molten alloy at the same time was evolved approx. $21.5 \mathrm{dm}^{3}$ of gases (fig. 1).

Differences of gases emissivity from both moulding sands may be due to the molecular structure of sodium carboxymethyl starches selected for the tests ie. a various share of sodium carboxymethyl group substituted [6]. Studies on the influence of alkaline metal ions on the process of thermal decomposition of natural polymers showed that the presence of the sodium ion in the structure may affect the efficiency of the overlap of dehydration, decarboxylation and charring of the material process [12].

The volume of gas generated from the $1 \mathrm{~kg}$ of moulding sand with binder based on resin Kaltharz U404 about the emissions of moulding sand CMS-NaL and CMS-NaH, was higher by about. 5.5 $\mathrm{dm}^{3}$ and $12.5 \mathrm{dm}^{3}$ respectively.

However, given the different part of the binding material in the selected moulding sands and after determining the volume of gas emitted from the thermal decomposition of $1 \mathrm{~g}$ of the binder (including any curing agent), it was found that CMS-Na can generate twice the smaller volume of gases than the cured resin Kaltharz U404 [11].

\subsection{Emission of BTEX compounds}

The results of determination of the content benzene, toluene, ethylbenzene and xylene emitted from $1 \mathrm{~g}$ of selected binder are summarized in Table 3.

Table 3.

Results of the content of selected aromatic hydrocarbons emitted from the binders

\begin{tabular}{llll}
\hline $\begin{array}{l}\text { Aromatic hydrocarbons } \\
\text { content in emitted gases, mg/g } \\
\text { binder }\end{array}$ & \multicolumn{2}{l}{ Type of binder } \\
\cline { 2 - 4 } & CMS-NaL & CMS-NaH & $\begin{array}{l}\text { Kaltharz } \\
\text { U404 }\end{array}$ \\
\hline Benzene & 8.93 & 9.63 & $25.98^{* *}$ \\
\hline Toluene & 0.51 & 0.31 & $3.85^{* *}$ \\
\hline Ethylbenzene & $0.00^{*}$ & $0.00^{*}$ & $0.02^{* *}$ \\
\hline Xylenes & 0.14 & 0.05 & $0.18^{* *}$ \\
\hline$*$ below the sensitivity of GC-FID device, & & \\
$* *$ resin cured by chemical agent $[11]$ & &
\end{tabular}

The results of quantitative determination of the compounds from the BTEX group indicated that from both starch products under the pouring molten cast iron into the moulds at $1300{ }^{\circ} \mathrm{C}$, regardless of the degree of substitution, benzene was generated in an amount of less than $10 \mathrm{mg}$ and $1 \mathrm{~g}$ of binder. The content of toluene and xylene emitted during decomposition of the CMS-Naн sample was, respectively, 1.5 and approx. 3 times lower compared to the test results from the decomposition of CMS-NaL This may be associated with higher amount of sodium ion from sodium carboxymethyl groups substituted in CMS-NaH structure, which reduces the yield of formation of volatile substances of higher molecular weight [12]. Comparing these results with the effect of the emission tests BTEX from $1 \mathrm{~g}$ of the cured urea-furan resin Kaltharz U404, it was found that the emission of benzene from CMS-Na, depending on the DS was between 2.7 and 2.9 times lower, and the content of toluene even 7.5 - 12.4 times lower. The content of xylenes emitted from the sample Kaltharz U404 were also determined at a higher level than from the samples of CMS-Na. Also, for the binder based on resin Kaltharz U404 the content of ethylbenzene was determined at $0.02 \mathrm{mg}$, but the presence of this aromatic hydrocarbon could not be recorded in all 
samples binder $\mathrm{CMS}-\mathrm{Na}$, or the content was below the sensitivity of the device.

\section{Conclusions}

The application of organic binders in the preparation of moulding sand or moulding core sands is often associated with the risk of emission of large amounts of harmful substances to the environment, it is important to search for binders, which are characterized by lower gas evolution and emission of the BTEX compounds.

The research of the emissivity of gases from moulding sands with starch binder CMS-Na, shows that that thermal decomposition of the binder was multi-stage and the maximum of gaseous products volume were generated in the first 100 seconds after pouring molten cast iron in moulds and it did not exceed 30 $\mathrm{dm}^{3}$ of $1 \mathrm{~kg}$ moulding sand with the suggested addition of binder.

It was noted that the level of gases emission from the moulds consisting of CMS-Na, regardless of the degree of substitution, during pouring molten cast iron is less than the level of emission from moulding sand with binder based on resin Kaltharz U404. The calculated emissions of gases from only $1 \mathrm{~g}$ of starch binder is 2.0 - 2.5 lower than from $1 \mathrm{~g}$ of cured resin Kaltharz U404.

Among the products of thermal decomposition of CMS-Na was revealed the presence of selected compounds from the group the BTEX (apart from ethylbenzene), and the efficiency of their formation may be associated with the presence of sodium originating from the sodium carboxymethyl group substituted into glucopyranose ring - the higher the degree of substitution, caused the lower the content of toluene and xylenes in products of decomposition of modified starch [12]. However, in comparison to the binder of Kaltharz U404 the amount of aromatic hydrocarbons emitted from the binder CMS-Na, in particular benzene and toluene, it is much lower [11]. Thus, based on the test results of the determination content the BTEX compounds, the starch binder CMS-Na in the considered range of degree of substitution can be assessed as a more environmentally friendly material than binder systems containing furan resins used in foundries.

\section{Acknowledgements}

The work was supported by the Dean Grant AGH No. 15.11.170.541

\section{References}

[1] Atanda, P.O., Akinlosotu, O.C. \& Oluwole, O.O. (2014). Effect of Some Polysaccharide Starch Extracts on Binding Characteristics of Foundry Moulding Sand. International Journal of Scientific \& Engineering Research. 5(3), 362-367.

[2] Beňo, J., Jelínek, P., Špirutová, N. \& Mikšovský, F. (2011).
Efficiency of additives of the polysaccharide type on physical properties of bentonite mixtures. Archives of Foundry Engineering. 11(1), 5-8.

[3] Zhou, X., Yang, J. \& Qu, G. (2007). Study on synthesis and properties of modified starch binder for foundry. Journal of Materials Processing Technology. 183(2-3), 407-411. DOI:10.1016/j.jmatprotec.2006.11.001.

[4] Grabowska, B., Sitarz, M., Olejnik, E., Kaczmarska, K. \& Tyliszczak, B. (2015). FT-IR and FT-Raman studies of cross-linking processes with $\mathrm{Ca}^{2+}$ ions, glutaraldehyde and microwave radiation for polymer composition of poly(acrylic acid)/sodium salt of carboxymethyl starch - In moulding sands, Part I. Spectrochimica Acta - Part A: Molecular and Biomolecular Spectroscopy. 135, 529-535. DOI: 10.1016/j.saa.2015.06.084.

[5] Grabowska, B., Sitarz, M., Olejnik, E., Kaczmarska, K. \& Tyliszczak, B. (2015). FT-IR and FT-Raman studies of cross-linking processes with $\mathrm{Ca}^{2+}$ ions, glutaraldehyde and microwave radiation for polymer composition of poly(acrylic acid)/sodium salt of carboxymethyl starch - In moulding sands, Part II. Spectrochimica Acta - Part A: Molecular and Biomolecular Spectroscopy. 151, 27-33. DOI: 10.1016/j.saa.2015.06.084.

[6] Kaczmarska, K., Grabowska, B., Drożyński, D., Bobrowski, A., Kurleto, Ż. \& Szymański, Ł. (2016). Modified polysaccharides as alternative binders for foundry industry. Metalurija. 55(4), 839-842.

[7] Barrios, S.E., Contreras, J.M., López-Carrasquero, F. \& Müller A.I. (2012). Chemical modification of cassava starch by carboxymethylation reactions using sodium monochloro acetate as modifying agent. Revista de la Facultad de Ingenieria U.C.V. 27(2), 97-105.

[8] Li, H.P., Zhang, S.S., Jiang, H., Li, B. \& Li, X. (2011). Effect of degree of substitution of carboxymethyl starch on diaspore depression in reverse flotation. Transactions of Nonferrous Metals Society of China (English Edition). 21(8), 1868-1873. DOI:10.1016/S1003-6326(11)60943-6.

[9] Holtzer, M., Dańko, J., Lewandowski, J.L., Solarski, W., Dańko R. Grabowska, B. Bobrowski, A., ŻymankowskaKumon, S., Sroczyński, A., Różycki, A. \& Skrzyński M. (2012). Patent Application No. P.398709. (in Polish).

[10] Kubecki, M., Holtzer, M. \& Żymankowska S. (2013). Investigations of the Temperature Influence on Formation of Compounds from the BTEX Group During the Thermal Decomposition of Furan Resin. Archives of Foundry Engineering. 13(2), 85-90.

[11] Dańko, R. (2012). Strength model of self-setting moulding sands with synthetic resins in an aspect of the integrated matrix recycling process. Gliwice: Archives of Foundry Engineering. (in Polish).

[12] Jakab, E. (2015). Analytical Techniques as a Tool to Understand the Reaction Mechanism. In M. S. \& R. K. S. A. Pandey, T. Bhaskar (Ed.), Recent Advances in Thermochemical Conversion of Biomass. Elsevier Ltd. DOI:http://dx.doi.org/10.1016/B978-0-444-63289-0.00003$\mathrm{X}$ 